\title{
Synthesis of CIS (CuInSe $)$ Based Materials for Solar Applications
}

\author{
Ali Murat Soydan ${ }^{D},{ }^{1}$ Pinar Yilmaz, ${ }^{2}$ and Bahadır Tunaboylu ${ }^{3}$ \\ ${ }^{1}$ Institute of Energy Technologies, Gebze Technical University, Gebze, Kocaeli, Turkey \\ ${ }^{2}$ Institute of Nanotechnology, Gebze Technical University, Gebze, Kocaeli, Turkey \\ ${ }^{3}$ Department of Industrial Engineering, Istanbul Sehir University, Dragos Kampusu Orhantepe Mahallesi, Turgut Ozal Bulvarl, \\ No. 21, Dragos, Kartal, Istanbul, Turkey \\ Correspondence should be addressed to Ali Murat Soydan; asoydan@gtu.edu.tr
}

Received 25 August 2017; Accepted 12 November 2017; Published 9 January 2018

Academic Editor: Ewa Schab-Balcerzak

Copyright (C) 2018 Ali Murat Soydan et al. This is an open access article distributed under the Creative Commons Attribution License, which permits unrestricted use, distribution, and reproduction in any medium, provided the original work is properly cited.

Nanopowders of copper indium diselenide were produced with five different organic solvents: ethylenediamine, triethanolamine, oleylamine, oleic acid, and polyetheramine. We successfully synthesized pure CIS nanopowders at a temperature of $240^{\circ} \mathrm{C}$ at three different durations of $10 \mathrm{~h}, 20 \mathrm{~h}$, and $40 \mathrm{~h}$ with a one-step process. This shorter time method offers important cost advantages in manufacturing. Polyetheramine and oleic acid were used for the first time in literature for CIS synthesis in an autoclave.

\section{Introduction}

Copper indium diselenide (CIS), $\mathrm{CuInSe}_{2}$, is one of the most important semiconductor materials used in thin film photovoltaic (PV) cells. CIS is becoming a promising candidate material for solar cell applications due to its high optical absorption coefficient, suitable direct band gap energy, and long term stability [1]. This semiconductor is a crucial material as an absorber layer and offers an important advantage. It enables production of low cost flexible thin film solar cells. CIS nanostructures and thin films were in the past produced using magnetron sputtering [2], co- evaporation [3], laser deposition [4], electron beam deposition [5], and also non-vacuum based methods. It is known that processes based on vacuum technology have some disadvantages such as high energy consumption, high processing temperature, necessity of ultrapure materials, and limitation in total area of films [6]. Other types of methods of synthesis involve methods such as electrodeposition [7], chemical deposition $[8,9]$, hydrothermal process [10], and solvothermal process $[11,12]$. It appears from earlier work that the solvothermal method is the simplest low-cost process for manufacturing and suitable for PV industry. The solvothermal process conditions for synthesizing CIS nanopowders influence its structure and surface properties [13]. Processes with multiple steps were experimented using different types of solvents such as ethylenediamine $[6,14-16]$, triethanolamine $[10,16]$, oleylamine [17-20], oleic acid [13], polyetheramine [21], citric acid, butylcarbitol, hydrazine [22], ammonium bromide [23], and hexadecylamine [24].

In this study, we used the solvothermal method based on dissolving metals or metal salts with organic solvents in an autoclave at low temperatures with a single-step process. Nanopowders were produced with five different organic solvents: ethylenediamine, triethanolamine, oleylamine, oleic acid and polyetheramine. We successfully synthesized pure CIS nanopowders at a temperature of $240^{\circ} \mathrm{C}$, at three different durations of $10 \mathrm{~h}, 20 \mathrm{~h}$, and $40 \mathrm{~h}$ with a one-step process.

\section{Experimental Method}

All chemicals (A. Aesar Co.) were used as received without further purification. Copper chloride $\left(\mathrm{CuCl}_{2}\right.$ anhydrous $98 \%$ ), indium chloride ( $\mathrm{InCl}_{3}$ anhydrous $98 \%$ ), gallium chloride $\left(\mathrm{GaCl}_{3}\right.$ anhydrous $\left.99 \%\right)$, and selenous acid $\left(\mathrm{H}_{2} \mathrm{SeO}_{3}\right.$ anhydrous $\left.98 \%\right)$ were used as precursors and anhydrous ethylenediamine, triethanolamine, oleylamine, polyetheramine, and oleic acid were used as organic solvents. 
In the experimental process, $\mathrm{CuCl}_{2}, \mathrm{InCl}_{3}, \mathrm{GaCl}_{3}$, and $\mathrm{H}_{2} \mathrm{SeO}_{3}$ (chemical mixture) were weighed according to the stoichiometric ratio of $1: 0.7: 0.3: 2$ in an argon filled glove box. All samples were prepared separately according to solvent characteristics.

2.1. Sample Prepared with Anhydrous Ethylenediamine. For preparation of sample with anhydrous ethylenediamine, $17.5 \mathrm{ml}$ anhydrous ethylenediamine and $2.5 \mathrm{ml}$ ethanol were added to chemical mixture in a glove box and dissolved for 30 minutes with magnetic stirring and then held for 5 minutes in an ultrasonic bath. Sample was loaded into a Teflon-lined stainless steel autoclave with $45 \mathrm{ml}$ capacity. The autoclave was sealed and maintained at $240^{\circ} \mathrm{C}$ for $10 \mathrm{~h}, 20 \mathrm{~h}$, and $40 \mathrm{~h}$ in an electric oven. After the reaction, the autoclave was allowed to cool to room temperature. CIS nanoparticles in a black colored ethylenediamine organic solution were subject to centrifugation at $6000 \mathrm{rpm}$ repeated four times and rinsed with distilled water and ethanol to remove the byproducts. The final black slurry was dried at $80^{\circ} \mathrm{C}$ for 8 hours in a drying oven.

2.2. Sample Prepared with Triethanolamine. For preparation of triethanolamine sample, $18 \mathrm{ml}$ ethanol, $2 \mathrm{ml}$ distilled water, and TEA were added to chemical mixture in a glove box and dissolved for 30 minutes with magnetic stirring before keeping in ultrasonic bath for 5 minutes. Sample was loaded into a Teflon-lined stainless steel autoclave with $45 \mathrm{ml}$ capacity. The autoclave was sealed and maintained at $240^{\circ} \mathrm{C}$ for $10 \mathrm{~h}, 20 \mathrm{~h}$, and $40 \mathrm{~h}$ in an electric oven. After the reaction, the autoclave was allowed to cool naturally to room temperature and CIS nanoparticles, in black color ethylenediamine organic solution, were collected after centrifugation at $8000 \mathrm{rpm}$ repeated 4 times and rinsed with distilled water and ethanol to remove byproducts. The final black slurry was dried at $80^{\circ} \mathrm{C}$ for 8 hours in a drying oven.

2.3. Sample Prepared with Oleylamine. For preparation of oleylamine sample, $20 \mathrm{ml}$ oleylamine was added to chemical mixture in a glove box and dissolved for 30 minutes with magnetic stirring before keeping in ultrasonic bath for 5 minutes. Sample was loaded into a Teflon-lined stainless steel autoclave with $45 \mathrm{ml}$ capacity. The autoclave was sealed and maintained at $240^{\circ} \mathrm{C}$ for $10 \mathrm{~h}, 20 \mathrm{~h}$, and $40 \mathrm{~h}$ in an electric oven. After the reaction, autoclave was allowed to cool naturally to room temperature and CIS nanoparticles, in black color ethylenediamine organic solution, were collected after centrifugation at $8000 \mathrm{rpm}$ repeated 4 times and rinsed with acetone to remove byproducts. The final black slurry was dried at $80^{\circ} \mathrm{C}$ for 24 hours in a drying oven.

2.4. Sample Prepared with Oleic Acid. For preparation of oleic acid sample, $20 \mathrm{ml}$ oleic acid, $2 \mathrm{ml}$ ethanol, and $1 \mathrm{ml}$ distilled water were added to chemical mixture in a glove box and dissolved for 30 minutes with magnetic stirring before keeping in ultrasonic bath for 5 minutes. Sample was loaded into a Teflon-lined stainless steel autoclave with $45 \mathrm{ml}$ capacity. The autoclave was sealed and maintained at $240^{\circ} \mathrm{C}$ for $10 \mathrm{~h}, 20 \mathrm{~h}$, and $40 \mathrm{~h}$ in an electric oven. After the reaction, autoclave was allowed to cool naturally to room temperature and CIS nanoparticles, in black color ethylenediamine organic solution, were collected after centrifugation at $8000 \mathrm{rpm}$ repeated 4 times and rinsed with acetone to remove byproducts. The final black slurry was dried at $80^{\circ} \mathrm{C}$ for 24 hours in a drying oven.

2.5. Sample Prepared with Polyetheramine. For preparation of $20 \mathrm{ml}$ polyetheramine sample $2 \mathrm{ml}$ ethanol and $1 \mathrm{ml}$ distilled water were added to chemical mixture in a glove box and dissolved for 30 minutes with magnetic stirring and then for 5 minutes at ultrasonic bath. Sample was loaded into a Teflon-lined stainless steel autoclave with $45 \mathrm{ml}$ capacity. The autoclave was sealed and maintained at $240^{\circ} \mathrm{C}$ for $10 \mathrm{~h}, 20 \mathrm{~h}$, and $40 \mathrm{~h}$ in an electric oven. After the reaction, autoclave was allowed to cool naturally to room temperature and CIS nanoparticles, in black color ethylenediamine organic solution, were collected after centrifugation at $8000 \mathrm{rpm}$ repeated 4 times and rinsed with distilled water, acetone, and ethanol mixture to remove byproducts. The final black slurry was dried at $80^{\circ} \mathrm{C}$ for 24 hours in a drying oven.

The crystal structure was characterized by X-ray diffraction (XRD). The morphology and size of synthesized CIS nanoparticles were characterized by scanning electron microscopy (SEM) equipped with an EDAX.

\section{Results and Discussion}

The oleylamine plays several roles during the synthesis of CIS. It enables control of the growth rate of the nanoparticles during reactions by forming a liquid-metal complex. It plays the role of a capping agent for the nanoparticles. It is thought to reduce the reactivity between $\mathrm{Cu}, \mathrm{In}, \mathrm{Ga}$, and Se reactants [19]. Also, it has a high boiling point and nitrogen containing compound. Because of these characteristics, it is a very good candidate solvent for synthesizing CIS nanopowders. The XRD patterns of synthesized CIS nanopowders for three different hours are shown in Figure 1. Resolved peaks became sharp and cleaner as the process time increased from $10 \mathrm{~h}$ to $40 \mathrm{~h}$.

3.1. Oleylamine. Figure 1 represents $\mathrm{X}$-ray diffraction patterns of $\mathrm{CuInSe}_{2}$ nanopowders synthesized at 3 different times $\left(10,20\right.$, and 40 hours) at constant temperature $\left(240^{\circ} \mathrm{C}\right)$ conditions. XRD data shows that synthesized powders are comprised of tetragonal CIS materials (JCPDS card number 040-1487). Each sample shows five major diffraction peaks located in the expected position for the (112), (204/220), $(116 / 312),(008 / 400)$, and $(228 / 424)$ crystal planes.

Pure tetragonal CIS powder was synthesized during the reaction at 10 hours; when time was increased to 20 hours a second phase tetragonal $\mathrm{CuGaSe}$ was observed. At 40 hours process time, the peak intensity was lower and $\mathrm{CuGaSe}$ phase disappeared. According to Hahn et al. [19], the atomic percentages of Se decrease with increasing reaction time, while that of Ga continuously increased. This could be explained by the slow vaporization of Se in solution with increasing reaction time because of its relatively high vapor pressure compared to other elements. Thus, the balance of 


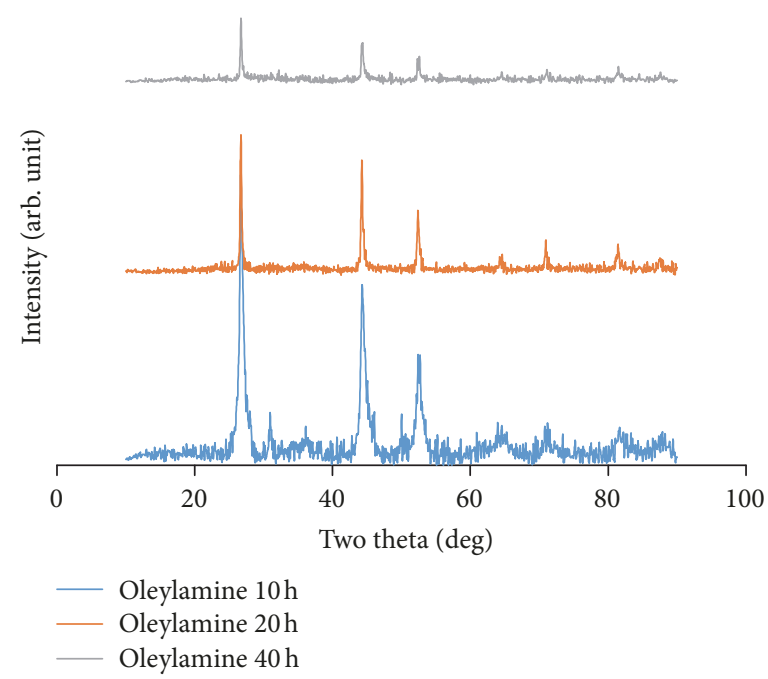

FIGURE 1: XRD pattern of synthesized CIS powder at $240^{\circ} \mathrm{C}$ for 10,20 , and 40 hours with oleylamine solvent.

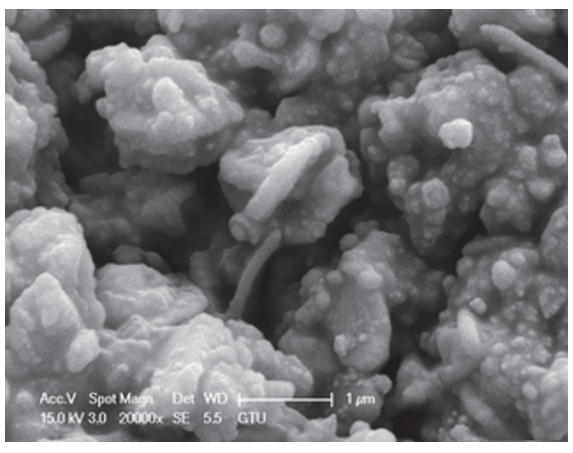

(a)

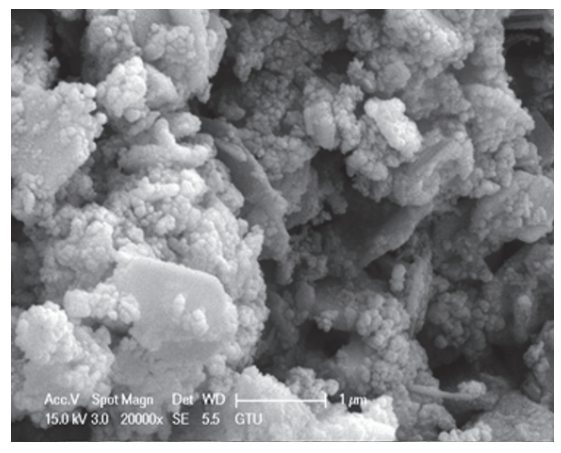

(b)

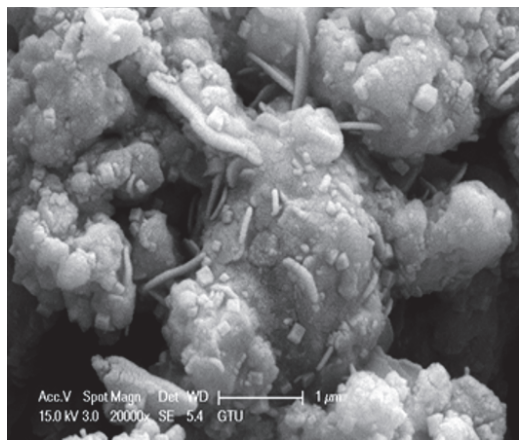

(c)

Figure 2: SEM micrographs of synthesized CIS powder at $240^{\circ} \mathrm{C}$ for (a) $10 \mathrm{~h}$, (b) $20 \mathrm{~h}$, and (c) $40 \mathrm{~h}$ with oleylamine solvent.

content shifted from Se to Ga during long reaction times. At 40 hours of reaction time, CuGaSe phase was not observed, but the intensity for $\mathrm{CuInSe}_{2}$ peak decreased.

To investigate the morphological properties of CIS nanoparticles, SEM images from the synthesized CIS powder were gathered and provided in Figure 2. Figure 2(a) shows agglomerated particles with the sizes $150-200 \mathrm{~nm}$. When the reaction time increased, particle sizes enlarged at $20 \mathrm{~h}$ (Figure 2(b)) and at 40 hours; the particle size becomes 1.5-2 microns. When the reaction time is prolonged, particle agglomeration was clearly observed as was also described in another study [19].

3.2. Triethanolamine (TEA). In Figure 3, XRD data shows that the synthesized powders were mainly comprised of CIS tetragonal chalcopyrite materials (JCPDS card number 401487). In a study by $\mathrm{Wu}$ et al. [10], it was indicated that cubic particles were observed at $160^{\circ} \mathrm{C}$, cubic shape particles decreased at $170^{\circ} \mathrm{C}$, and CIS tetragonal shape was formed at $200^{\circ} \mathrm{C}$.

In this study, based on XRD data from Figure 3 at $10 \mathrm{~h}$, pure CIS phase is observed with $0.5-1$ micron spherical particles, worm-like, irregular shaped nanoparticles as shown in Figure 4(a). At 20 hours' time reaction, $200-400 \mathrm{~nm}$ range, worm-like, irregular shaped nanoparticles are observed (Figure 4(b)). From XRD data for 40 hours' time reaction, the orthorhombic and the cubic structures occurred with low intensity CIS phase and woolen ball shape particles similar to described by Khanaki et al. [17] were observed on SEM images in Figure 4(c).

3.3. Oleic Acid. CIS nanoparticles were synthesized with oleic acid as a solvent, which has a similar molecular structure to different functional group as Hahn et al. [13] described earlier. Figure 5 shows the XRD patterns of CIS particles prepared in an oleic acid solution at $240^{\circ} \mathrm{C}$ for 10,20 , and 40 hours. XRD data shows that the synthesized powders were comprised of tetragonal CIS materials (JCPDS card number 040-1487). Each sample shows three major diffraction peaks located in the expected position for (112), (204/220), and $(116 / 312)$ crystal planes. Figure 6 provides information about microstructures of synthesized CIS powder at $240^{\circ} \mathrm{C}$ for $10 \mathrm{~h}$, $20 \mathrm{~h}$, and $40 \mathrm{~h}$.

At $10 \mathrm{~h}$ process time, three different phases were observed. They were tetragonal CuGaInSe, tetragonal $\mathrm{CuInSe}_{2}$, and tetragonal $\mathrm{Cu}_{3} \mathrm{Se}_{2}$ phases. At $20 \mathrm{~h}$ process, pure tetragonal 


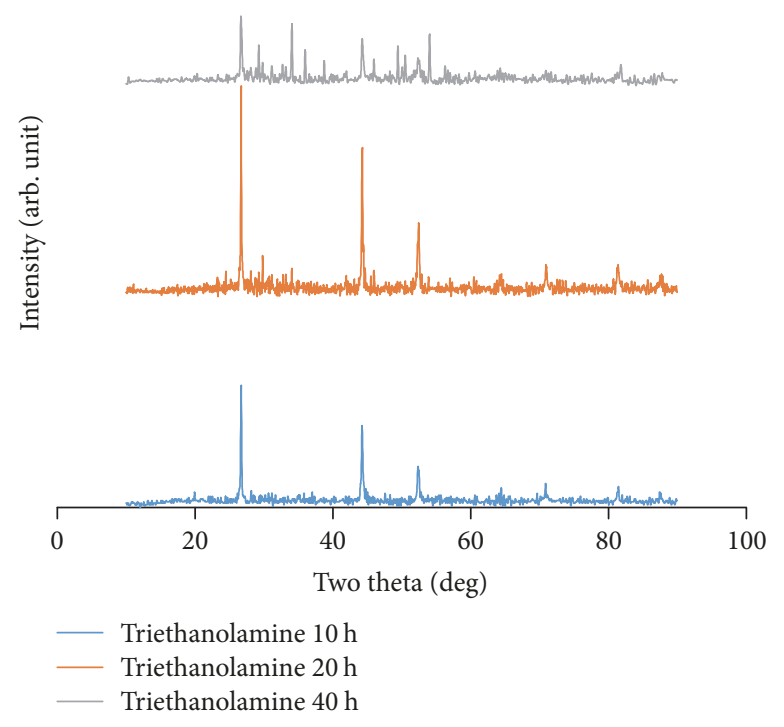

FIGURE 3: XRD pattern of synthesized CIS powder at $240^{\circ} \mathrm{C}$ for 10,20 , and 40 hours with triethanolamine solvent.

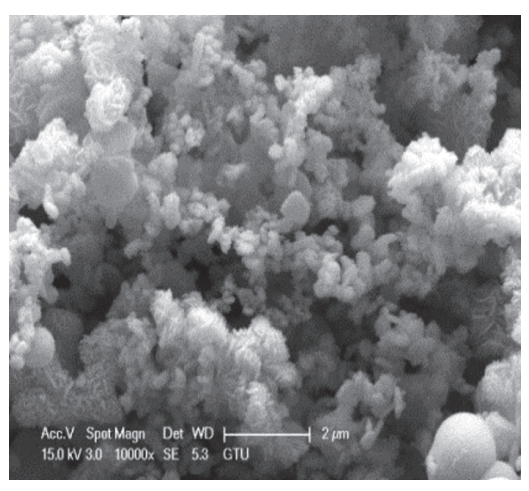

(a)

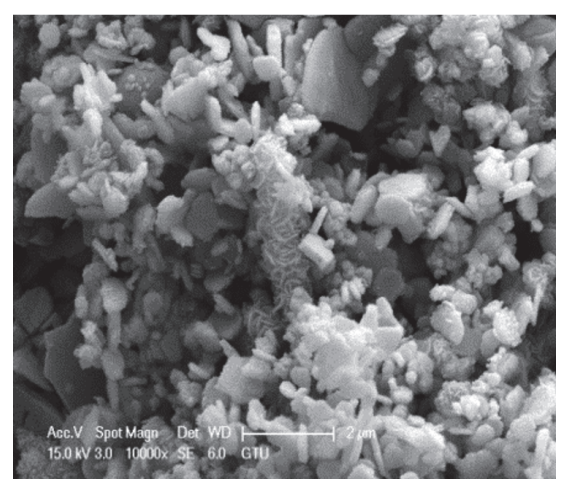

(b)

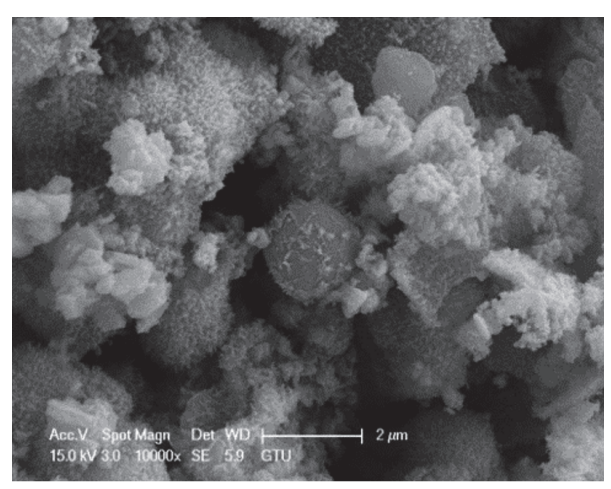

(c)

FIGURE 4: SEM micrographs of synthesized CIS powder at $240^{\circ} \mathrm{C}$ for (a) $10 \mathrm{~h}$, (b) $20 \mathrm{~h}$, and (c) $40 \mathrm{~h}$ with triethanolamine solvent.

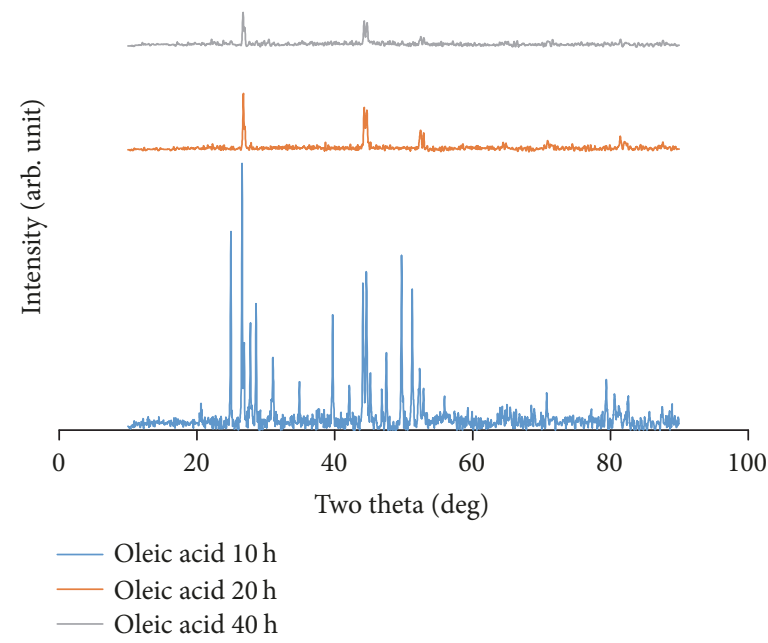

FIgURE 5: XRD pattern of synthesized CIS powder at $240^{\circ} \mathrm{C}$ for 10,20 , and 40 hours with oleic acid. 


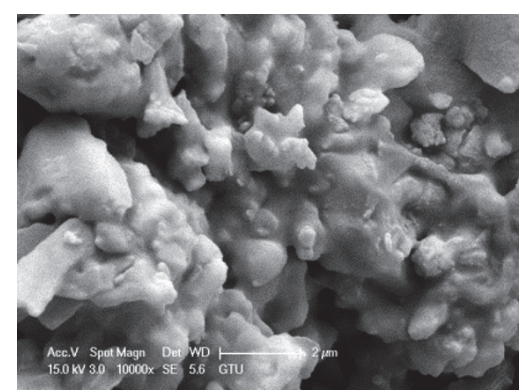

(a)

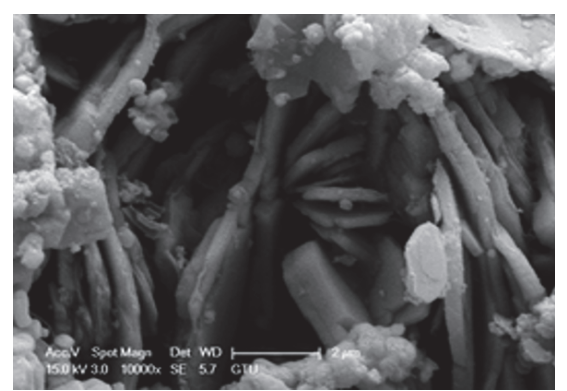

(b)

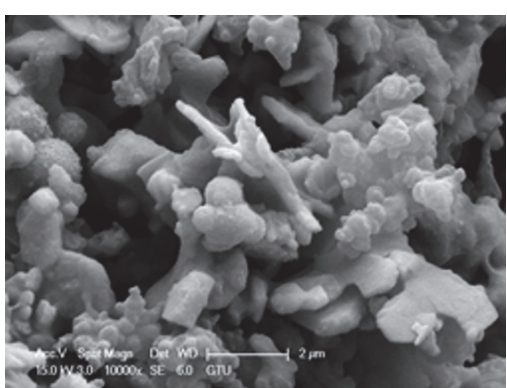

(c)

FIGURE 6: SEM micrographs of synthesized CIS powder at $240^{\circ} \mathrm{C}$ for (a) $10 \mathrm{~h}$, (b) $20 \mathrm{~h}$, and (c) $40 \mathrm{~h}$ with oleic acid.

CIS phase was observed. At $40 \mathrm{~h}$ process, tetragonal CIS particles were observed with lower intensity compared to $20 \mathrm{~h}$ process. Hahn et al. [13] synthesized CIS powder with oleic acid in a three-neck flask at $250-300^{\circ} \mathrm{C}$. Polygonal and octahedral shape particles were obtained. In this study, all CIS powder had tetragonal shapes. From the SEM images, first 10 hours' time CIS and umangite $\left(\mathrm{Cu}_{3} \mathrm{Se}_{2}\right)$ were observed at 1-2 micron size; at 20 hours' time reaction plate-like shape CIS was observed similar to reported by $\mathrm{Gu}$ et al. [14]. The morphology changes from polygonal to octahedral plate-like shape with increasing reaction temperature. At 40 hours' reaction time, only CIS phase was observed with agglomerated large particles with the long process time. When the reaction time increased, the intensity of CIS gets decreased because it is thought that In leaves the structure. For this study, the optimum condition was $20 \mathrm{~h}$ reaction time.

3.4. Polyetheramine. Polyetheramine is a rare solvent with double amine-capped polymer with a high boiling point resulting in strong chelation. Wang et al. [21] used polyetheramine solvent for CIGS synthesizing at $250^{\circ} \mathrm{C}$ in three-neck flask for 20 hours' time. In this study, all the reaction occurred in an autoclave for $10 \mathrm{~h}, 20 \mathrm{~h}$, and $40 \mathrm{~h}$.

Figure 7 illustrates the X-ray diffraction patterns of $\mathrm{CuInSe}_{2}$ powders synthesized at $240^{\circ} \mathrm{C}$ for 10 hours in an autoclave. It shows that tetragonal CIS 40-1487 and CGS 0310456 phases were observed with large plate-like and irregular small particles (Figure 8(a)). When the time increased to $20 \mathrm{~h}$, both CIS and CGS powders intensity get decreased besides particle growing with agglomeration (Figure 8(b)). Xray data at $40 \mathrm{~h}$ shows In and Se released from the structure to form $\mathrm{CuSe}_{2}$ and InSe phases with agglomerated big platelike particles. A particle size of $200-300 \mathrm{~nm}$ is observed for longer reaction time of $40 \mathrm{~h}$ at Figure 8(c).

3.5. Ethylenediamine (EDA). EDA is most preferred solvent for synthesizing CIGS, CIS powders with solvothermal method. Zhang et al. [15] produced CIS nanopowders with EDA at $210-230^{\circ} \mathrm{C}$ range for 20 hours. In addition, Chen et al. [16] obtained pure CIS phase at $200^{\circ} \mathrm{C}$ for 15 hours.

The tetragonal CGS, hexagonal GaSe, Se and CuSe phases with $150-200 \mathrm{~nm}$ agglomerated particles were observed at processing time of $10 \mathrm{~h}$, based on Figures 9 and $10(\mathrm{a})$. Advancing process time to 20 hours yielded CIGS and $\mathrm{CuSe}_{2}$.

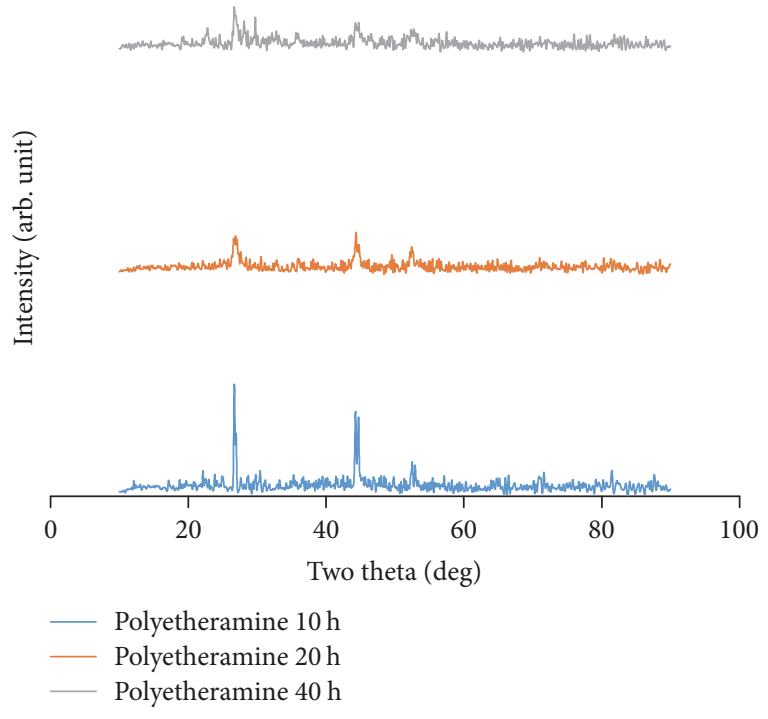

FIGURE 7: XRD pattern of synthesized CIS powder at $240^{\circ} \mathrm{C}$ for 10 , 20 , and 40 hours with polyetheramine.

However, at 40 hours' process only second phases such as indium selenide and copper selenite were observed. Chen et al. [16] comment that if longer time of solvothermal process was employed, the peak belonging to the CIS chalcopyrite phase was strengthened and longer reaction time does favor the crystallization of CuInSe $e_{2}$ phase and high purity can be obtained. But in this study, in a longer time reaction CIS peak has disappeared. Parallel to work done by Gu et al. [14], CGS seed was obtained up to $230^{\circ} \mathrm{C}$ for 20 hours' process but disappeared at 40 hours' reaction process.

\section{Conclusions}

Five different solvents such as oleylamine, oleic acid, triethanolamine, polyetheramine, and ethylenediamine were successfully used to synthesize tetragonal CIS powders with solvothermal method in an autoclave in the same conditions. It has been found that oleylamine is the best solvent based on the X-ray data from processing at $240^{\circ} \mathrm{C}$ for 10,20 , and 40 hours. CIS phase was successfully synthesized using five different solvents. According to results at these processing 


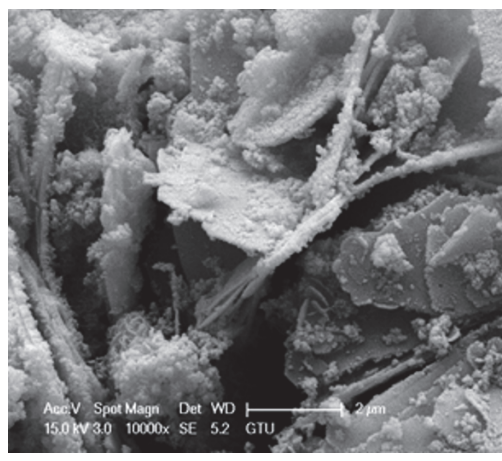

(a)

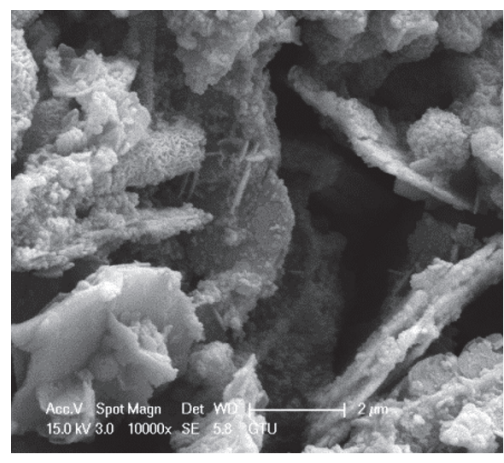

(b)

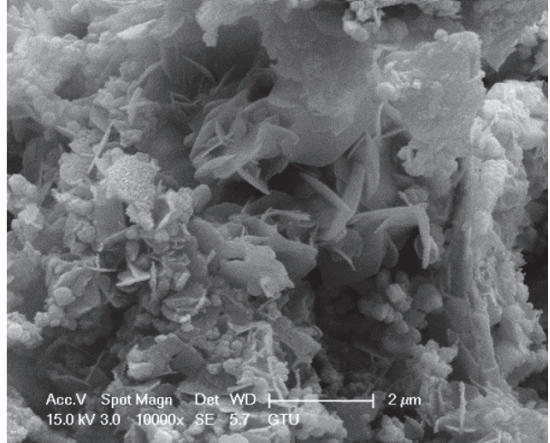

(c)

FIGURE 8: SEM micrographs of synthesized CIS powder at $240^{\circ} \mathrm{C}$ for (a) $10 \mathrm{~h}$, (b) $20 \mathrm{~h}$, and (c) $40 \mathrm{~h}$ with polyetheramine.

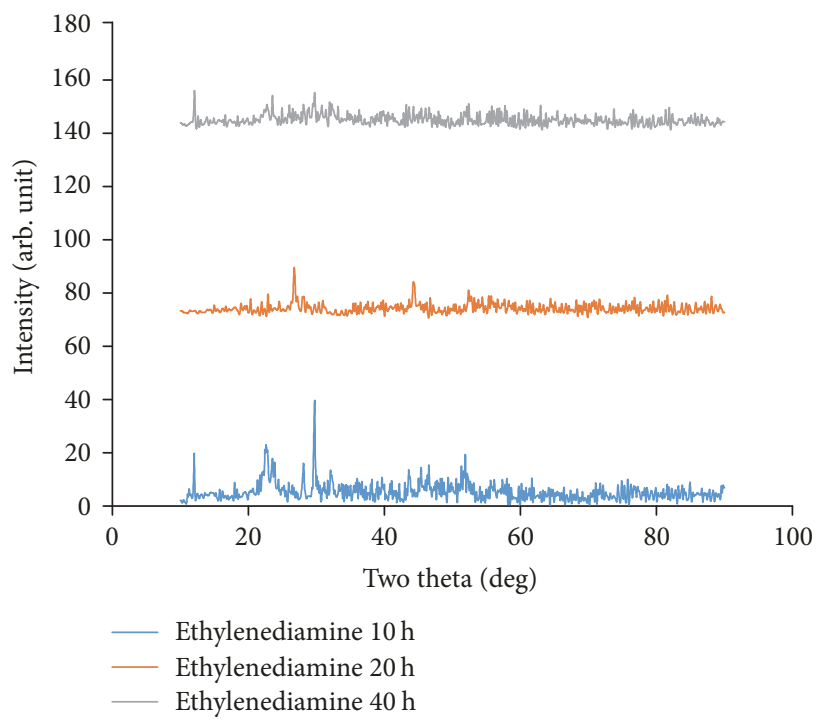

FIGURE 9: XRD pattern of synthesized CIS powder at $240^{\circ} \mathrm{C}$ for 10,20 , and 40 hours with ethylenediamine.

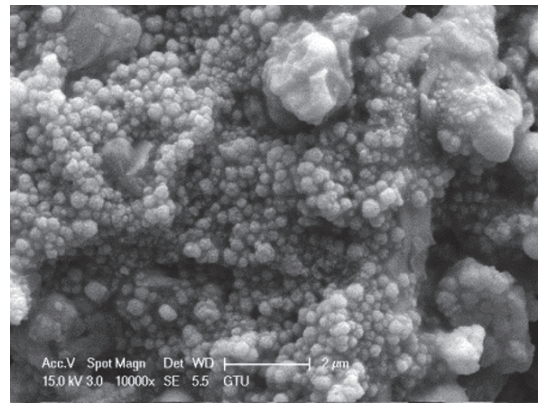

(a)

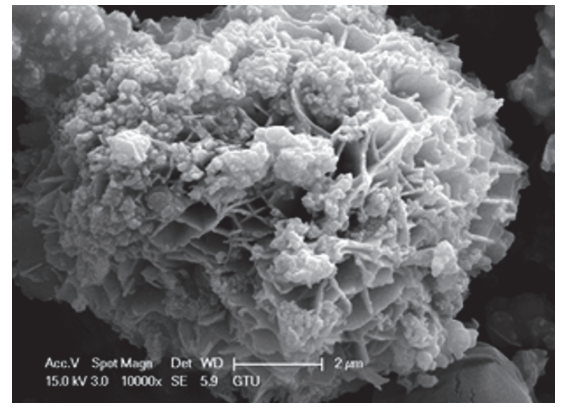

(b)

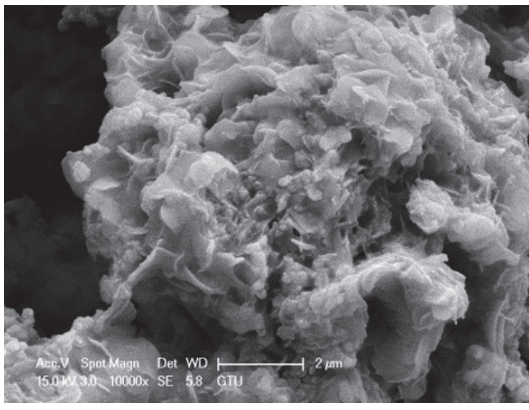

(c)

Figure 10: SEM micrographs of synthesized CIS powder at $240^{\circ} \mathrm{C}$ for (a) $10 \mathrm{~h}$, (b) $20 \mathrm{~h}$, and (c) $40 \mathrm{~h}$ with ethylenediamine.

conditions, best desirable properties were obtained in this order: (1) oleylamine (10 hours), (2) triethanolamine (20 hours), (3) oleic acid (20 hours), (4) polyetheramine (10 hours), and (5) ethylenediamine (20 hours). Polyetheramine and oleic acid were used for the first time in literature for CIS synthesis in an autoclave. Other methods were studied in the literature; the chemical reaction occurs in a three-necked flask which takes much long time for a successful synthesis.

\section{Conflicts of Interest}

The authors declare that they have no conflicts of interest. 


\section{References}

[1] J.-Y. Park, "One pot solvothermal synthesis of colloidal Cu(In1$\mathrm{xGax}) \mathrm{Se}_{2}$ (CIGS) quantum dots for solar cell applications," Journal of Alloys and Compounds, vol. 629, pp. 162-166, 2015.

[2] L. Miaomiao, C. Fanggao, L. Chao, X. Cunjun, W. Tianxing, W. Jihao et al., "CIS and CIGS thin films prepared by magnetron sputtering," Procedia Engineering, vol. 27, pp. 12-19, 2012.

[3] J. Lindahl, U. Zimmermann, P. Szaniawski et al., "Inline $\mathrm{Cu}(\mathrm{In}, \mathrm{Ga}) \mathrm{Se} 2$ co-evaporation for high-efficiency solar cells and modules," IEEE Journal of Photovoltaics, vol. 3, no. 3, pp. 11001105, 2013.

[4] Y. Zhao, H. Li, Y. Zhu et al., "Pulsed laser deposition of singlecrystalline Cu7In3/CuIn0.8Ga0.2Se2 core/shell nanowires," Nanoscale Research Letters, vol. 9, no. 1, p. 650, 2014.

[5] M. Venkatachalam, M. D. Kannan, S. Jayakumar, R. Balasundaraprabhu, and N. Muthukumarasamy, "Effect of annealing on the structural properties of electron beam deposited CIGS thin films," Thin Solid Films, vol. 516, no. 20, pp. 6848-6852, 2008.

[6] W.-H. Hsu, H.-I. Hsiang, and S. Yu, "Crystallite formation mechanism of $\mathrm{CuIn}(\mathrm{Se}, \mathrm{S}) 2$ synthesized using solvothermal method," Ceramics International, vol. 41, no. 2, pp. 3208-3213, 2015.

[7] A. M. Fernandez, M. E. Calixto, P. J. Sebastian, S. A. Gamboa, A. M. Hermann, and R. N. Noufi, "Electrodeposited and selenized $\left(\mathrm{CuInSe}_{2}\right)$ (CIS) thin films for photovoltaic applications," Solar Energy Materials and Solar Cells, vol. 52, no. 3-4, pp. 423-431, 1998.

[8] M. Kar, H. W. Hillhouse, and R. Agrawal, "Chemical liquid deposition of $\mathrm{CuInSe}_{2}$ and $\mathrm{CuIn}(\mathrm{S}, \mathrm{Se}) 2$ films for solar cells," Thin Solid Films, vol. 520, no. 16, pp. 5431-5437, 2012.

[9] R. H. Bari, L. A. Patil, P. S. Sonawane, M. D. Mahanubhav, V. R. Patil, and P. K. Khanna, "Studies on chemically deposited $\mathrm{CuInSe}_{2}$ thin films," Materials Letters, vol. 61, no. 10, pp. 20582061, 2007.

[10] C.-H. Wu, F.-S. Chen, S.-H. Lin, and C.-H. Lu, "Preparation and characterization of $\mathrm{CuInSe}_{2}$ particles via the hydrothermal route for thin-film solar cells," Journal of Alloys and Compounds, vol. 509, no. 19, pp. 5783-5788, 2011.

[11] M. Wang, S. K. Batabyal, H. M. Lim, Z. Li, and Y. M. Lam, "Formation of $\mathrm{CuIn}(\mathrm{SxSe1-x}) 2$ microcrystals from $\mathrm{CuInSe}_{2}$ nanoparticles by two step solvothermal method," Journal of Alloys and Compounds, vol. 618, pp. 522-526, 2015.

[12] Y. Liu, D. Kong, J. Li, C. Zhao, C. Chen, and J. Brugger, "Preparation of $\mathrm{Cu}(\mathrm{In}, \mathrm{Ga}) \mathrm{Se}_{2}$ Thin Film by Solvothermal and Spin-coating Process," Energy Procedia, vol. 16, pp. 217-222, 2012.

[13] J.-S. Hahn, G. Park, J. Lee, and J. Shim, "Synthesis of CuInSe ${ }_{2}$ nanoparticles in an oleic acid solution for application in thin film solar cells," Journal of Industrial and Engineering Chemistry, 2014.

[14] S.-I. Gu, H.-S. Shin, D.-H. Yeo, Y.-W. Hong, and S. Nahm, "Synthesis of the single phase CIGS particle by solvothermal method for solar cell application," Current Applied Physics, vol. 11, no. 1, pp. S99-S102, 2011.

[15] L. Zhang, W. Zhang, J. Liu et al., "Solvothermal synthesis of chalcopyrite CuIn $0.7 \mathrm{Ga} 0.3 \mathrm{Se} 2$ nanoparticles and the studies on reaction mechanism and structure defects," Materials Chemistry and Physics, vol. 147, no. 3, pp. 390-394, 2014.

[16] H. Chen, S.-M. Yu, D.-W. Shin, and J.-B. Yoo, "Solvothermal synthesis and characterization of chalcopyrite $\mathrm{CuInSe}_{2}$ nanoparticles," Nanoscale Research Letters, vol. 5, no. 1, pp. 217223, 2010.

[17] A. Khanaki, H. Abdizadeh, and M. R. Golobostanfard, "Effects of process parameters on the synthesis and characterization of $\mathrm{CuIn}_{1-x} \mathrm{Ga}_{x} \mathrm{~S}_{e 2}$ nanopowders produced by new modified solvothermal method," Materials Science in Semiconductor Processing, vol. 16, no. 6, pp. 1397-1404, 2013.

[18] H.-C. Wang, C.-C. Wang, S.-W. Feng, L.-H. Chen, and Y.-S. Lin, "Synthesis of CIGS thin film by solvothermal route," Optical Materials Express, vol. 3, no. 1, pp. 54-66, 2013.

[19] J.-S. Hahn, S.-H. Lee, M.-S. Seo, D.-K. Choi, J. Lee, and J. Shim, "Synthesis of CuInxGal - xSe2 nanoparticles in organic solvent for thin film solar cells," Thin Solid Films, vol. 546, pp. 279-283, 2013.

[20] J. Tang, S. Hinds, S. O. Kelley, and E. H. Sargent, "Synthesis of colloidal $\mathrm{CuGaSe}_{2}, \mathrm{CuInSe}_{2}$, and $\mathrm{Cu}(\mathrm{InGa}) \mathrm{Se}_{2}$ nanoparticles," Chemistry of Materials, vol. 20, no. 22, pp. 6906-6910, 2008.

[21] C.-J. Wang, S.-C. Shei, and S.-J. Chang, "Novel solution process for synthesis of CIGS nanoparticles using polyetheramine as solvent," Materials Letters, vol. 122, pp. 52-54, 2014.

[22] J. H. Woo, H. Yoon, J. H. Cha, D. Y. Jung, and S. S. Yoon, "Electrostatic spray-deposited CuInGaSe ${ }_{2}$ nanoparticles: effects of precursors' Ohnesorge number, substrate temperature, and flowrate on thin film characteristics," Journal of Aerosol Science, vol. 54, pp. 1-12, 2012.

[23] S. H. Mousavi, T. S. Müller, R. Karos, and P. W. De Oliveira, "Faster synthesis of CIGS nanoparticles using a modified solvothermal method," Journal of Alloys and Compounds, vol. 659, pp. 178-183, 2016.

[24] M. Ahmadi, S. S. Pramana, L. Xi, C. Boothroyd, Y. M. Lam, and S. Mhaisalkar, "Evolution pathway of CIGSe nanocrystals for solar cell applications," The Journal of Physical Chemistry C, vol. 116, no. 14, pp. 8202-8209, 2012. 

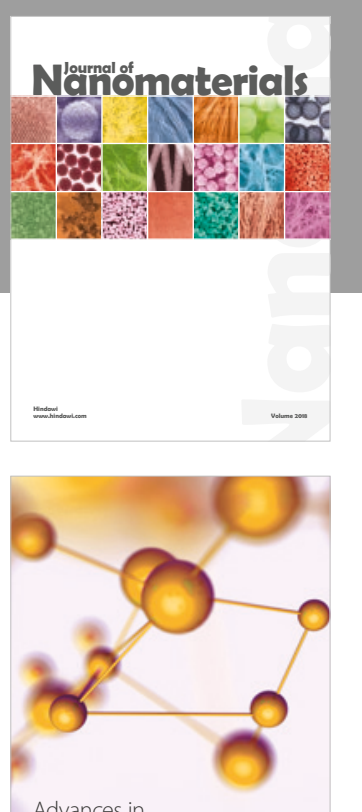

Physical Chemistry
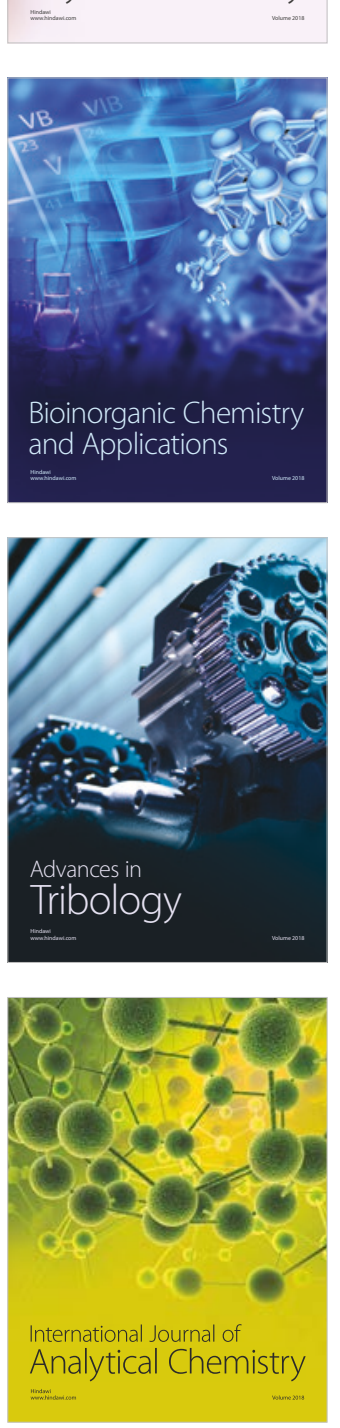

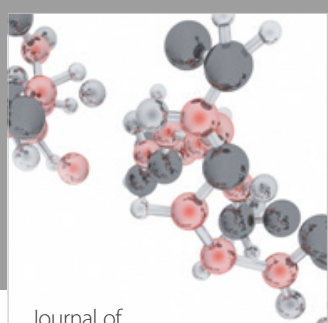

Analytical Methods

in Chemistry

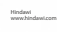

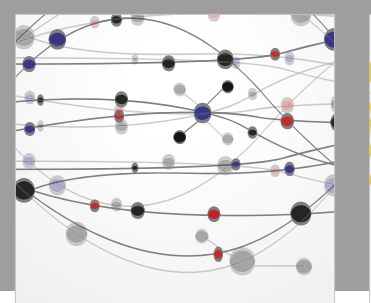

The Scientific World Journal

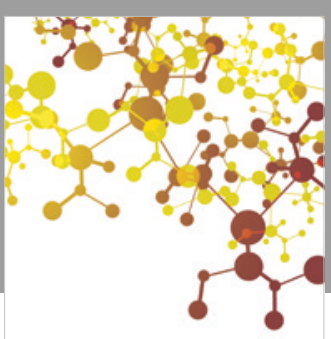

Journal of

Applied Chemistry
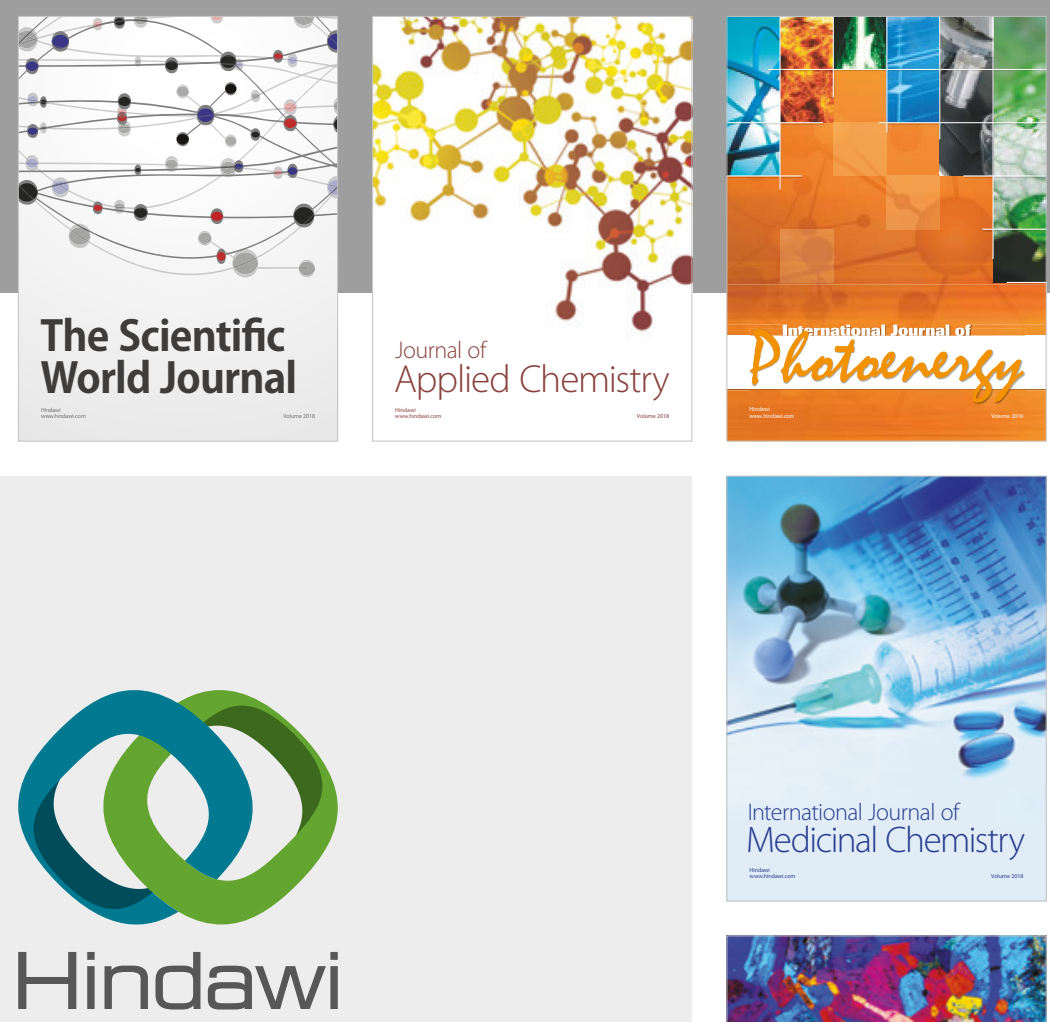

Submit your manuscripts at

www.hindawi.com
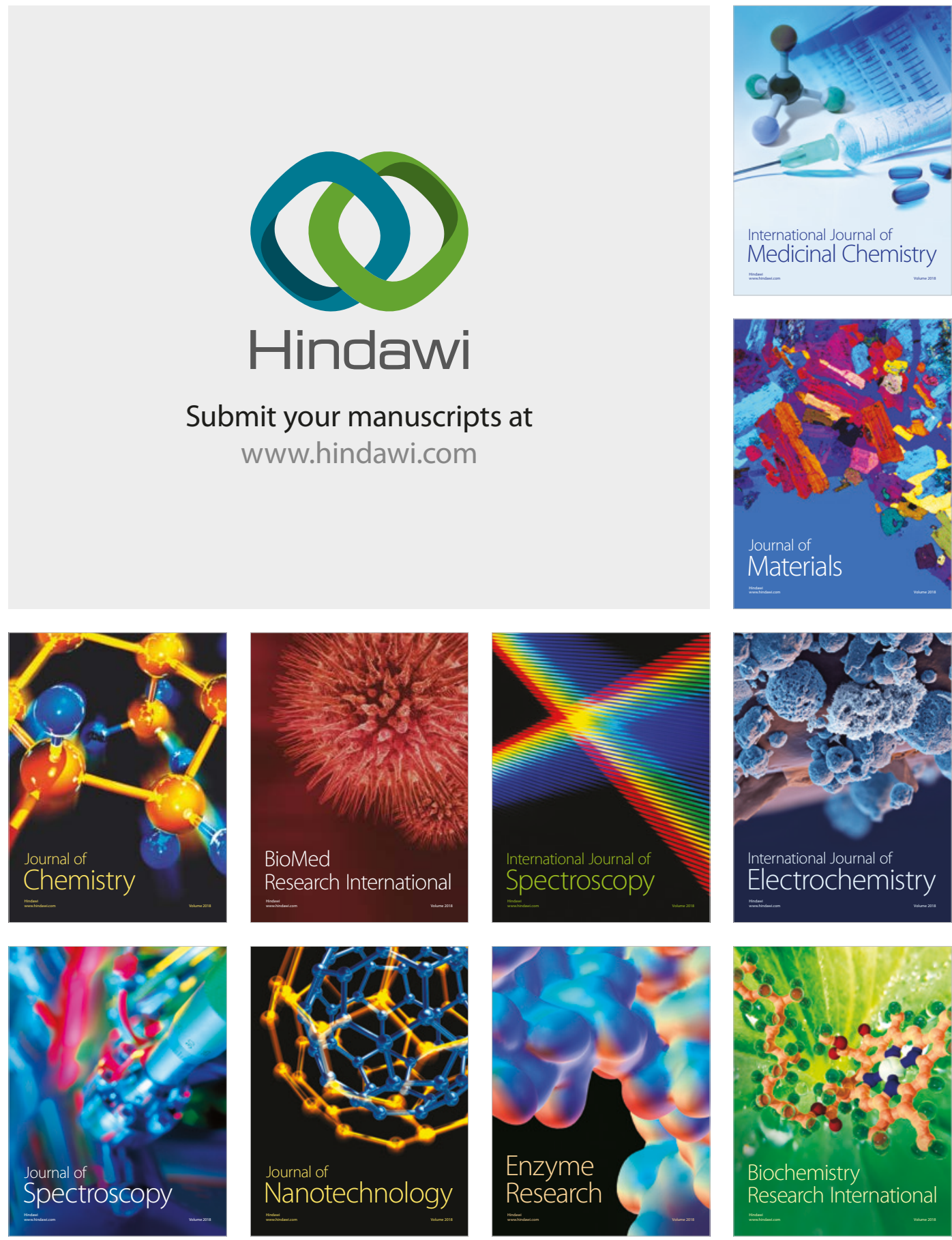
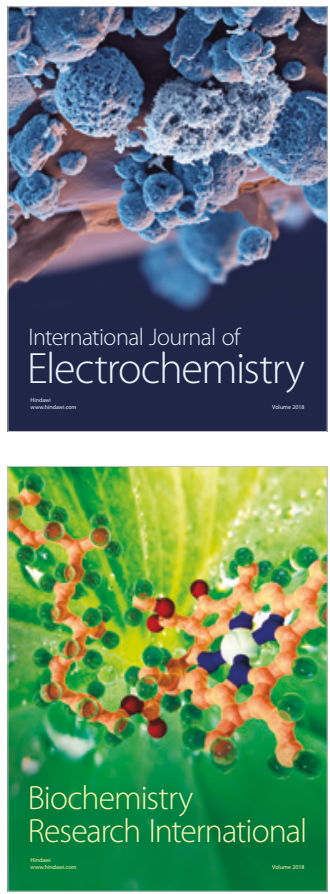